\title{
Features of the survey and monitoring of the technical condition of cultural heritage objects based on the BIM model
}

\author{
Sergey Ekba* \\ Moscow State University of Civil Engineering, 129337, Moscow, Russia
}

\begin{abstract}
In Russia, Building Information Modeling (BIM) is becoming a mandatory requirement for the construction of new buildings. There is a positive experience in the implementation and examination of projects with BIM. A number of Russian companies have already introduced and are actively using information design technologies in their activities. However, at the current moment, the use of BIM in Russia is at the start. This paper shows examples of the use of BIM and laser scanning in the development of scientific and project documentation for cultural heritage sites. The paper shows the stages of engineering research. A comparison is made between traditional methods of building inspection and with the method of laser scanning. The key advantages of using a BIM model at the design stage, restoration and subsequent stages of the object's life cycle are shown. The promising areas of application of BIM technologies, laser scanning technologies at different stages of the life cycle of an object (buildings, structures, utilities) have been identified.
\end{abstract}

\section{Introduction}

According to the information from the Moscow Government's Open Data Portal, there are more than 8000 cultural heritage objects (CHOs) on the territory of the metropolis, of which 4055 are buildings. According to the Committee for State Control, Use and Protection of Historical and Cultural Monuments of the Government of St. Petersburg, almost 9000 objects are located on the territory of St. Petersburg. However, there is no data in open sources on the technical condition of load-bearing structures, foundations and bases of buildings from this list. At the same time, in accordance with the requirements of the legislation of the Russian Federation, security obligations are established for the owner or other legal holder of the cultural heritage object included in the register. These obligations include protection, conservation, repair, restoration.

If we talk about property rights to cultural heritage objects, then they belong to investors or the state. Taking into account the fact that a significant part of such objects is located in the historical centers of megacities (for example, Moscow and St. Petersburg), investors and owners are trying to make their assets as attractive as possible in terms of economic

* Corresponding author: ekba.s.ig@gmail.com 
efficiency. In most cases, buildings that are objects of cultural heritage in the centers of megacities are used as multifunctional complexes, usually with the organization of retail, office and residential premises (apartments) in them, which, in turn, inevitably necessitates the development of project documentation, in particular, a project of adaptation for a modern use (Figures 1).

One of the main tasks at the design stage is the information obtained from the results of the engineering and technical survey of the CHO. The key indicators of the project - the timing and cost of design work - depend on the completeness and reliability of the data, methods and means of measurement, technologies used at this stage of survey. To solve such complex problems, the most optimal tool is BIM technologies in conjunction with laser scanning.

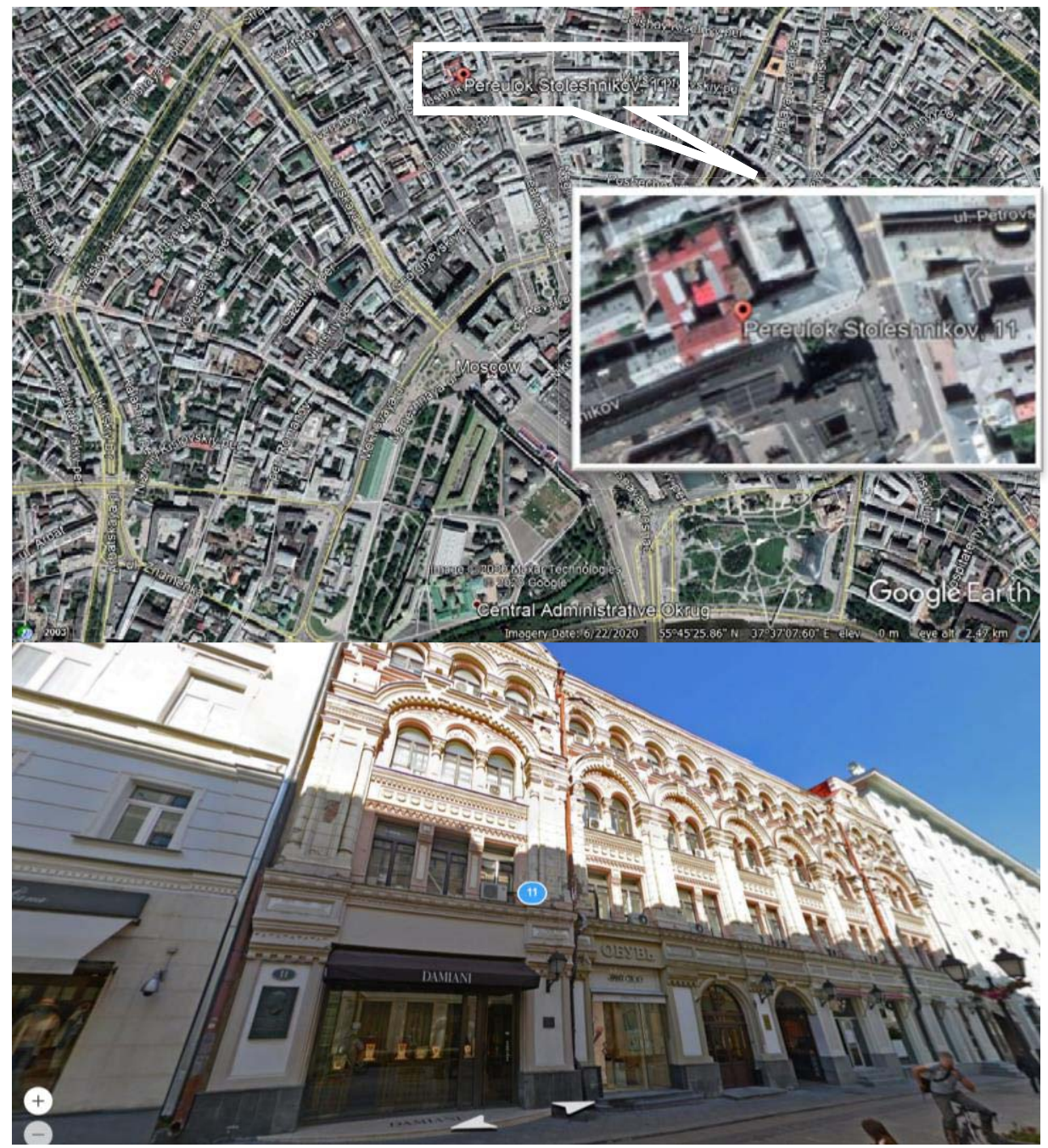

Fig. 1. Photos of a subject to inspection. Moscow, Russia

Scan to BIM is the process to make a BIM model from an architectural survey (TLS or SFM), usually identified as going from a point cloud model to a volumetric model associated to a database, which is a complete $3 \mathrm{D}$ model of the building that describes the 
state of the building at the time the survey was made. Modeling the building in BIM implies a better comprehension of the building, and the 3D model allows redressing and completing the 3D survey information.

Even though this process is long and implies to have a minimum comprehension of how the building works, making a BIM comes with some benefits regarding the management and maintenance of the heritage buildings and the possibility to work with others groups or the client in a cooperative way with regard to make improvements or details in the modeled elements. Some articles bring up advantages of the Scan to BIM in architecture, regarding analysis, clash detection, integrations of datasets, integration of intangible information, interoperability, multidisciplinary teams, design consistency, cost estimations, knowledgeenriched visualization of heritage artefacts, monitorization projects, planning and coordinating project resources, recording the model deliverables between different LoDs, as standard reference for project players planning model development and the interface between software [1-3]. In complementary disciplines, there are other advantages like emergency management, service and business continuity, disaster recovery, piping, etc. BIM created models, starting from the knowledge of the building, have allowed storage, within a single "virtual archive", of the historical information of the components and the information necessary for its future maintenance, updatable over time [4].

\section{Materials and methods}

The main objective is to identify the works published in the last 10 years that address these two subjects (BIM and HBIM) using a Systematic Literature Review (RSL). This study used the term (string) search: («damage» OR «restoration» OR «conservation») AND («BIM» $\mathrm{OR}$ «HBIM» $\mathrm{OR}$ «Building Information Modeling» OR «Building Information Model»). The search was restricted to journal articles, congress articles, book chapters and established as criterion publications with the occurrence of terms to least in the title, keywords, or abstract. The databases used were: ScienceDirect, Scopus and Web of Science [14].

Modeling of architectural structures.

BIM-based software products are mainly intended for the construction of new buildings, but they can also open up opportunities for the design and management of cultural heritage objects [5]. Each cultural heritage object has its own architectural identity due to its distinct past and historical changes over time. Therefore, quite often $\mathrm{CHO}$ is characterized by very complex and irregular shapes, most of which do not correspond to classical geometric laws. For example, the thickness of the walls of one building can vary in height and length. In addition, some elements are the result of the impact of time and various external factors (solar radiation, erosion, exposure to temperatures), which leads to a change and the formation of a new and complex shape. Modeling them is even more difficult with conventional modeling software and takes a significant amount of time. A number of studies in this area have been criticized precisely because of the losses that arise when using libraries to model existing buildings, rather than historical ones [6]. Hence, architectural components have LODs that depend on the purpose of the project. Modeling of architectural elements with a high level of detail (LOD 400, LOD 500) is not required to use the model during the operation and maintenance phase. Thus, one of the important tasks is the development of libraries of architectural elements within the framework of a specific $\mathrm{CHO}$, as well as the choice of the optimal level of detail (LOD) in order to minimize costs at the stage of developing scientific and project documentation.

Modeling of engineering systems. 
Maintenance systems make the working and living environment comfortable and safe. Architecture and engineering networks and systems should be equally taken into account not only during planning, but also during the construction phase.

In historic buildings, it is more difficult to withstand all these rules and requirements compared to new construction, since there are many architectural constraints.

Practice shows that technical rooms are located in the attic, in the basement or in rooms that are not of architectural value [7]. Therefore, space for technological equipment is limited in size and load on structures, which complicates the implementation and modeling of the project. The use of systems engineering is fundamental to cultural heritage objects. This fact becomes the key to creating a safe building and optimizing restoration measures, especially in cases of emergency technical condition of the facility. At this stage of the project, it is important to preserve all parametric properties, update the changes made to the model, and render it in the 3D model. Thus, the compatibility between the embedded model and special building management and maintenance software ensures the longevity of the data sets, achieving important results in the operation and maintenance phase.

In 2017, the Ministry of Construction of Russia approved an action plan for the implementation of BIM technologies in the Russian Federation. At the same time, a number of regulatory documents "Information Modeling in Construction" were developed, describing the main provisions, rules, terms of the information model of an object at various stages of the life cycle. In addition, in the same year, requirements for information models were developed, and in 2019 they were approved by Moscow State Expertise. Thus, at the moment, industry experts have starting points for the active implementation of BIM technologies not only in the design of new construction, but in the direction of reconstruction and restoration of buildings and structures. This paper presents the research results obtained on the basis of a survey of cultural heritage sites in Moscow, describes the methods and means of measurement used in the conducted engineering and technical studies, and also summarizes the experience of leading Russian companies using BIM in design.

In order to obtain all the necessary information about the design object and assess the list of measures to preserve the part or the whole $\mathrm{CHO}$, complex engineering and technical studies are conducted, depending on the complexity of the object and the urban planning situation. They include:

- examination of foundations and bases with the determination of their condition and bearing capacity;

- examination of load-bearing and enclosing structures, including determination of the structural system, methods of connecting structures, characteristics of materials and bearing capacity;

- measurement work;

- materials science research, including determination of physical, physicochemical, physicomechanical characteristics of materials and their damage caused by various factors;

- $\quad$ studies of the temperature and humidity conditions of the object;

- $\quad$ engineering and environmental studies.

Nowadays, most companies use traditional methods of control (destructive and nondestructive) and measurement tools, as well as software for 2D drawings (floor plans, facades, sections, units) when conducting engineering and technical surveys. It should be noted that it is recommended to use non-destructive methods when conducting studies.

However, traditional approaches and measuring instruments do not always provide the required accuracy and speed of measurements, and in the study of CHOs, which often have complex design and architectural solutions, the problem becomes almost impossible to solve. 
During the engineering and technical survey at the $\mathrm{CHO}$, the specialist has a number of key tasks in order to obtain reliable and complete data subsequently presented in the reporting documentation (Figures 2).

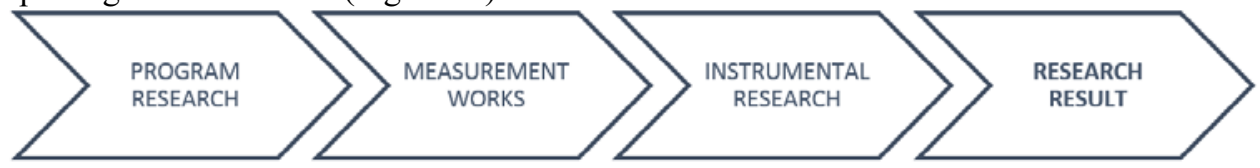

Fig.2. Algorithm engineering survey

For example, traditional measuring tools when performing measurement work are tape measures, rulers, laser rangefinders. But when carrying out work on cultural heritage objects, measure such elements that are complex in cross-section, with a complex surface and located at a height (cornice, frieze, architrave, capital, columns, etc.) using these measuring tools is not possible. As studies have shown, in such cases, the most effective is the use of laser scanning with subsequent processing of the resulting point cloud and the creation of a BIM model of the object (building) of the study based on it.

HBIM is the adaptation of BIM applied to heritage buildings. The first step in HBIM is to define the most standard possible template in order to have a model that can be shared with other disciplines. Even though there are a lot of initiatives for its standardization (COTAC, LEGEND-HBIM...), in general, they adapt to the BIM characteristics. One of the biggest differences is the incorporation of phases converted in historical periods, where the actual phase is the common one for all the cases [8-9].

In architectural heritage restoration and conservation, it is not possible or optimal the parametrization of families, that is why it is important to distinguish between ordinary families and modelled families. There exist catalogues of antique elements parametrized as a base to be adapted, even so, in most of the cases, the elements have to be modelled from scratch. This context could justify modeling in BIM heritage buildings if all the heritage buildings are modeled in BIM, the HBIM library on antique elements would be extended and making HBIM models would become more efficient every time [10-12].

The main goals of laser scanning, as a measurement tool during measurement work, are:

- determination of the shape, configuration, overall dimensions of complex architectural elements for the purpose of their subsequent recreation, creation of models for study, including for printing on 3D printers;

- execution of high-precision dimensional drawings as part of engineering and technical inspection of building structures;

- $\quad$ determination of the scope of dismantling works (if necessary);

- determination of the actual state of the building and its elements before the start of construction work;

- $\quad$ creation of a BIM building model for further design based on it [13];

- creation of orthophoto maps of interior elements for their further restoration, recreation, coordination with departmental structures (Department of Cultural Heritage, etc.);

- $\quad$ creation of presentation materials for investors, departmental structures.

The use and filling of the BIM model with data at all stages of complex scientific research on the preservation and/or adaptation of the object allows not only complementing the results of laser scanning, but also allowing the entire design process to be conducted more efficiently. The created BIM model can be used at all subsequent stages of the object's life cycle - conservation/adaptation, restoration, operation, repair.

\section{Results and Discussions}


The result of the stage of measurement work using laser scanning is a BIM model, the degree of detail and the amount of data contained in it increases in the process of performing an engineering study. A graphical display of model changes is shown in Figure 3.
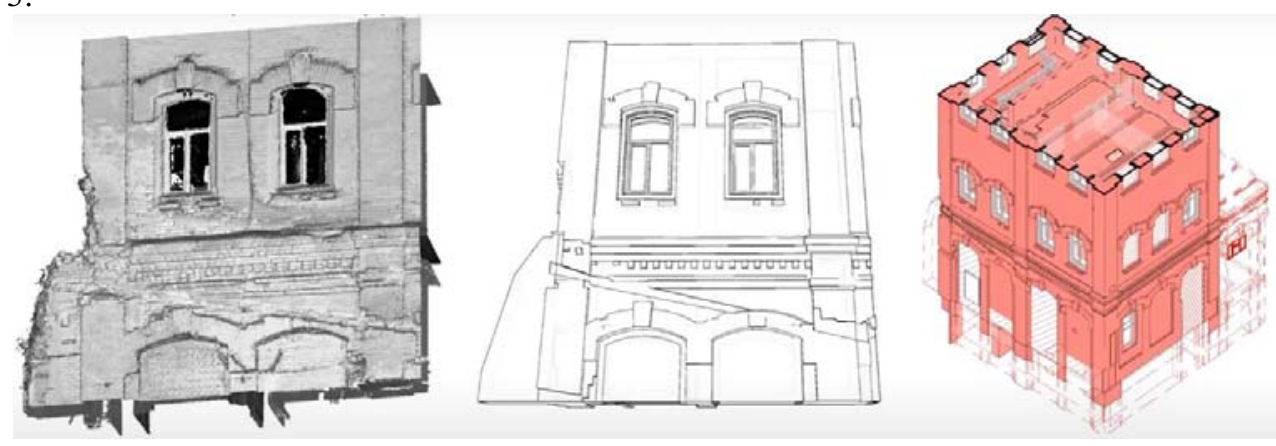

Fig. 3. Point clouds, drawing, BIM model

The next stage of engineering study is instrumental examination. In the course of fullscale work at the stage, additional data on the geometric dimensions (thickness of the finishing layer and coatings, the dimensions of the cross-section of the supporting structures are specified) and the physical and mechanical properties of the materials of the structures are entered into the BIM model, which are subsequently used to perform verification calculations of structures.

As part of the instrumental survey, the opening of the protective and finishing layers, the sounding of the ground, and the cutting of the pits are performed. In addition, samples of soil and groundwater are taken to assess their composition and aggressiveness, the strength of structural materials, reinforcement parameters (pitch, diameter) are determined, the physical, mechanical and chemical characteristics of the steel of the structures are determined, mycological studies are carried out.

On the basis of the data obtained, for structures that are in a limited operational and emergency state, verification calculations are carried out taking into account the actual physical and mechanical characteristics of the materials of these structures, loads acting on structures and their design scheme.

As part of the study, verification calculations of structures were carried out on the basis of data from a BIM model made in Revit 2019 with subsequent integration into the LIRASAPR software.

As a result of all stages of work (Figures 2), we received the initial data for the development of a scientific and technical project. In the further development of the restoration and adaptation project, the previously created BIM model again reveals its advantages for the project participants. In particular, in practice, there are CHOs in which the subject of protection is a part of a building, for example, a facade or a separate wall. The use of BIM allows tight control over such elements at all stages of design. In addition, we get a high level of specification detailing, and, as a result, an accurate determination of the estimated cost of the designed work, as well as the possibility of variant design. The efficiency of interaction between project participants increases, and the project management process is simplified.

The BIM model is further used to develop a work organization project. Thanks to the integration of Revit with Navisworks, we have the opportunity to receive and, if necessary, optimize 5D work schedules, which include time and costs, as well as receive 3D animation and graphic images with high visibility of each construction process - strengthening structures, moving buildings, etc. (Figure 4). 


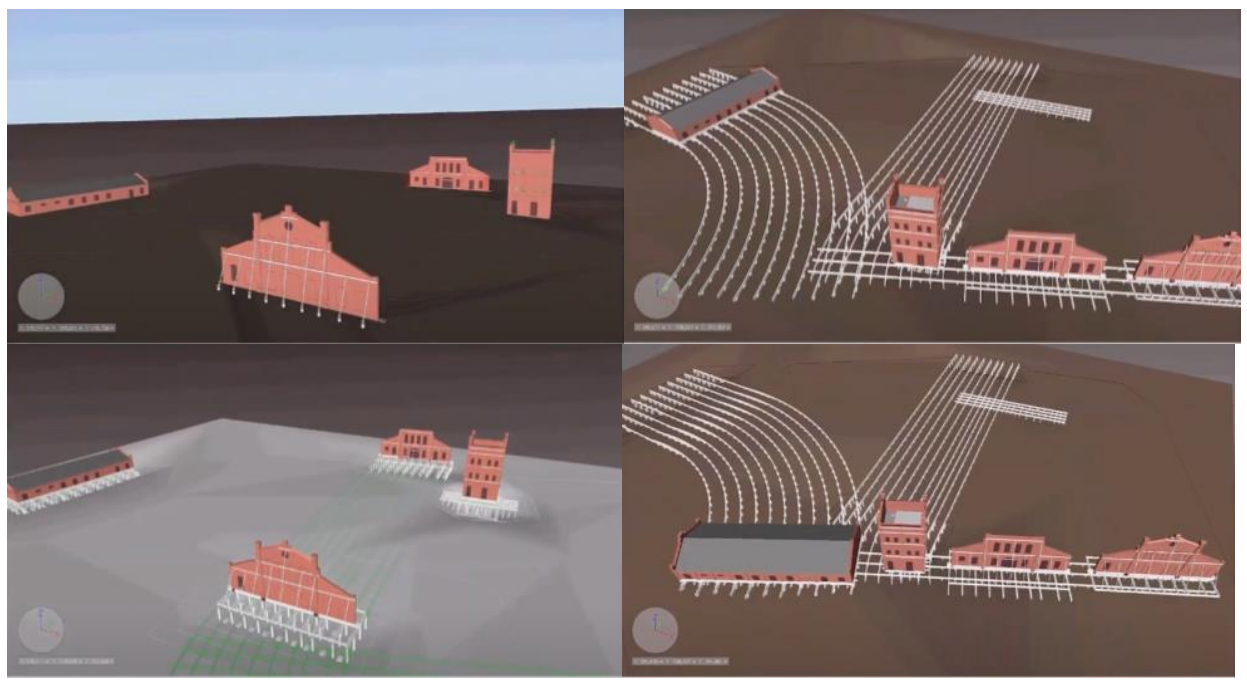

Fig. 4. Integration software Revit and Navisworks

BIM model of the $\mathrm{CHO}$ allows implementing two more important functions of the project - monitoring and control. As mentioned earlier, the main task of protecting the $\mathrm{CHO}$ is its preservation. Preservation in this case means measures aimed at ensuring the physical safety and preservation of the historical and cultural value of a cultural heritage object, providing for conservation, repair, restoration, adaptation of a cultural heritage object for modern use and including research, exploration, design and production work, scientific management of the work on the preservation of the cultural heritage object, technical and designer supervision of these works.

Monitoring of the technical condition of the $\mathrm{CHO}$ is organized in the following cases: The CHO is in a working technical condition, but at the same time it falls into the zone of influence of new construction or reconstruction of objects located nearby; before the start of restoration, repair and other work.

The time period for the functioning of monitoring should make it possible to determine the trends and intensity of the development of processes.

Thus, the use of a BIM model in conjunction with laser scanning makes it possible to obtain accurate data on the position of an object and its individual elements at any time (before and after construction work), as well as to monitor the performance of work on the $\mathrm{CHO}$ and supervise the adopted design decisions.

\section{Conclusions}

Thus, the studies presented in the paper show the high efficiency of using the BIM model in the framework of complex engineering and technical research of cultural heritage objects and the development of scientific and design documentation.

Development of scientific and design documentation (including the restoration and adaptation project) using a BIM model gives a significant positive effect:

- the ability to use BIM360 - coordinated work of project participants without time and geographic reference. Given the COVID-2019 situation facing the whole world, this advantage is the key one;

- $\quad$ reduction of design costs;

- simple identification and elimination of errors/collisions of all sections of the project; 
- $\quad$ openness of project stages for all participants, including investors (Figure 5)

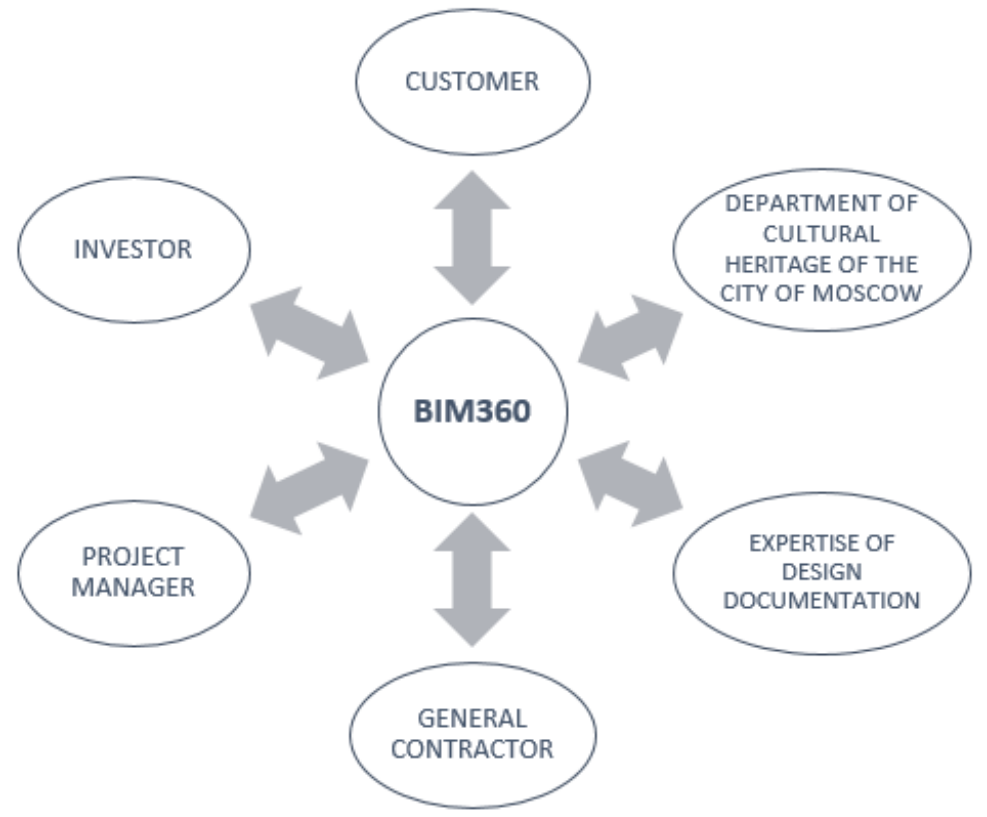

Fig. 5. Interaction of the project participants

Thus, the use of BIM when conducting an engineering and technical survey of $\mathrm{CHO}$ provides a number of significant advantages over the traditional approach:

- the most reliable data about the research object;

- on the basis of an array of reliable data, the exact terms of design are determined, and in the future, the terms of restoration;

- $\quad$ precise determination of the estimated cost of design work to preserve the CHO.

In addition, the model obtained in the course of BIM and developed as part of an engineering and technical survey, is the basis for the next stage of the object's life cycle operation. This BIM model allows:

- $\quad$ monitoring the technical condition of the cultural heritage object;

- $\quad$ predicting the performance of conservation work - repair, restoration;

- $\quad$ managing site visits;

- $\quad$ ensuring comprehensive security - fire security, intrusion, etc.

\section{References}

1. I. Palomar, M. Zornoza, Comparativa entre el modelo bim geométrico y el modelo de malla en el campo de la arquitectura patrimonial: beneficios e inconvenientes, EUBIM Congreso Internacional BIM, Encuentro de Usuarios BIM, 82-92 (2015)

2. M. Acierno, S. Cursi, D. Simeone, D. Fiorani, Architectural heritage knowledge modelling: An ontology-based framework for conservation process, Journal of Cultural Heritage 24, 124-133 (2017)

3. A. Maisarah, M. Kamsiah, S. Khairusy, M. Muhammad, Heritage Building Preservation Through Building Information Modelling: Reviving Cultural Values 
Through Level of Development Exploration, Planning Malaysia: Journal of the Malaysian Institute of Planners 16(2), 62 - 72 (2018)

4. Tomasello, Nicoletta \& Russo, Giuseppe \& Caporlingua, Massimo \& Cascone, Stefano, use of the bim methodology for the maintenance and valorisation of historical and architectural heritage (the case study of the Jesuits College IN Catania, 2018)

5. N. Hichri, C. Stefani, L. De Luca, P. Veron, Review of the "AS-BUILT BIM" Approaches, Int. Soc. Photogramm. Remote Sens XL-5/W1, 107-111 (2013)

6. C. Dore, M. Murphy, Current state of the art Historic Building Information Modelling, Int. Arch. Photogramm. Remote Sens. Spat. Inf. Sci. XL22-2/W5, 190 (2017)

7. M. Serraino, E. Lucchi, Energy efficiency, heritage conservation, and landscape integration, The case study of the San Martino Castle in Parella (Turin, Italy), Energy Procedia 133, 424-434 (2017)

8. A. Osello, G. Lucibello, F. Morgagni, HBIM and Virtual Tools: A New Chance to Preserve Architectural Heritage, Buildings 8, 12. (2018) doi.org/10.3390/buildings8010012

9. J. García, R. Marc, E. Salvador, Interpretación de las fases constructivas propias de la metodología BIM como épocas históricas para edificios patrimoniales, EUBIM, 4050

http://ocs.editorial.upv.es/index.php/EUBIM/EUBIM2015/paper/viewFile/1538/384

10. I. Jordan, P. Tzortzopoulos, J. García, E. Pellicer, Protocol to Manage HeritageBuilding Interventions Using Heritage Building Information Modelling (HBIM) https://www.mdpi.com/2071-1050/10/4/908

11. C. Eastman, P. Teicholz, R. Sacks, K. Liston, BIM Handbook: A Guide to Building Information Modeling for Owners, Managers, Designers, Engineers and Contractors (2nd edn. Wiley, Hoboken, 2011)

12. Zoran Puko et al 2017 IOP Conf. Ser.: Mater. Sci. Eng. 245062028

13. Sergey Ekba, E3S Web of Conferences 110, 01081 (2019)

14. R. Brumana, D. Oreni, A. Raimondi, A. Georgopoulos, A. Breggiani, From survey to HBIM for documentation, dissemination and management of built heritage: the case study of St. Maria in Scaria d'Intelvi., In: Digital Heritage International Congress, Marseille, France, 497-504 (2013)

15. O. Salosin, Gamayunova, A. Mottaeva, EMMFT 2019, IOP Publishing 1614, 012028 (2020) doi:10.1088/1742-6596/1614/1/012028 